\title{
Editorial
}

\section{Welcome to Interventional Neurology}
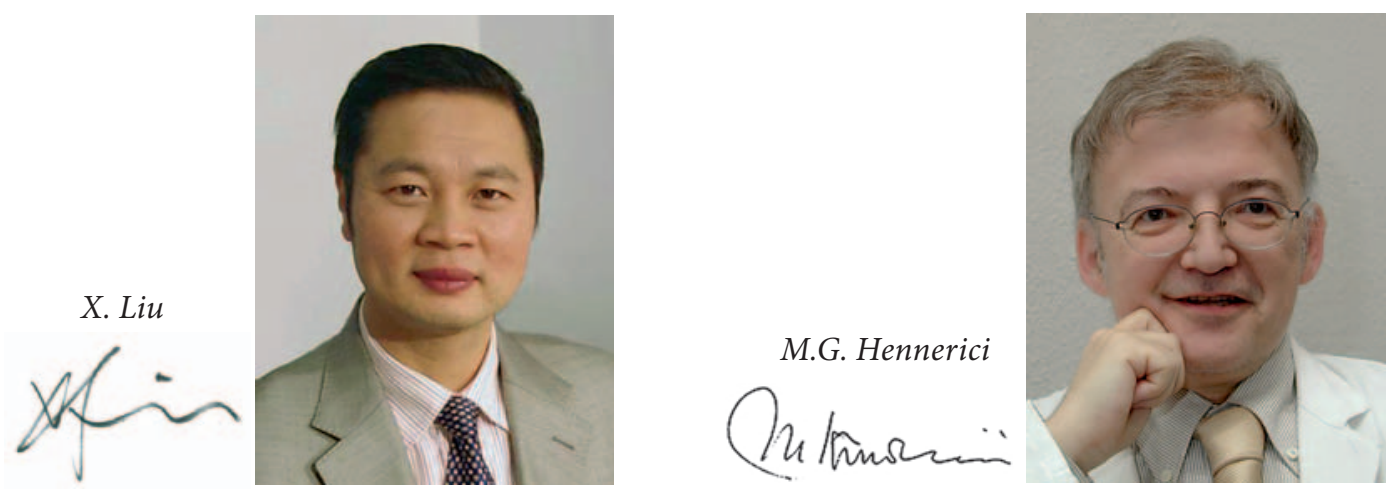

Interventional neurology is a subspecialty of neurology in which minimally invasive procedures are performed under radiologic or ultrasonographic guidance. Some of these procedures are for diagnostic purposes, and others are for therapeutic purposes.

Endovascular procedures are evolving as an important strategy for diagnosing and treating many neurological diseases, especially cerebrovascular diseases such as atherosclerotic occlusive carotid disease, intracranial aneurysm, and cranial arteriovenous malformations. In recent years, catheter-based intra-artery thrombolysis to facilitate recanalization of proximal cerebral artery occlusion has increasingly been used. Furthermore mechanical embolectomy with rapidly developing different devices has been attempted in treating ischemic stroke patients within or outside the time windows of IV thrombolysis after stroke onset. Despite encouraging reports as well as disappointing outcome data, we still lack evidence-based data as to whether this invasive procedure alone or following frustrane IV thrombolysis ('bridging concept') offers a good benefit/risk ratio in selected patients. In contrast, endovascular coil embolization has become a treatment of choice for unruptured intracranial aneurysm along with standard neurosurgical procedures. Endovascular embolization can decrease the size of the arteriovenous malformation, reducing intraoperative blood loss, and target blood vessels that might not be surgically accessible.

Along with world-wide developing strategies published in disseminated journals depending on the medical background of their authors (radiology, neuroradiology, neurosurgery, neurology, etc.) a specific journal for review, update, and discussion is lacking. For renovating and generalizing the knowledge in interventional neurology, this new journal might be useful.

On the occasion of the 21st European Stroke Conference we launch Interventional Neurology, the first international peer-reviewed journal of its kind to focus exclusively on interventional procedures in managing neurological diseases. Interventional Neurology will start to publish invited and submitted reviews, hypotheses, meta-analyses, and controversies along with commentaries and letters to the editor quarterly. This will be followed by original articles addressing new issues of this topic. New developments in methodology and techniques will be important resources for information exchange in this academic platform.

You are welcome to contribute to Interventional Neurology.

$X$. Liu, Nanjing

M.G. Hennerici, Mannheim 


\section{《介入神经病学》主编致辞}

介入神经病学是神经病学的一个重要分学科。这类介入技术是以放射线、超声 或其他影像技术为引导，实现疾病的诊断或者治疗。

血管内介入技术正在成为诊断、治疗包括脑血管病（如动脉弹样硬化性颈动脉 闭塞性病变、颅内动脉瘤、颖内动静脉畸形等) 在内的多种神经系统疾病的重要手 段。近些年，基于导管的动脉内溶栓治疗已被广泛应用于脑动脉近端闭塞性病变的 再通。随着各种设备器材的飞速发展, 机械取栓被尝试用于治疗不适宜静脉溶栓的 缺血性卒中。目前血管内介入治疗的临床试验结果喜忧参半, 目前尚缺乏循证医学 的证据支持动脉内介入治疗能对特定疾病人群带来益处。对于未破裂的颅内动脉瘤, 血管内弹簧圈栓塞已成为可与神经外科血管夹闭术疗效相当的手术策略。外血管内 栓塞可缩减动静脉畸形血管团体积, 减少术中出血量, 并且能够达到外科手术无法 达到的血管部位。

由于目前尚缺乏一本血管介入领域的专门杂志, 科研工作者根据其医学背景(放 射学、神经放射学、神经外科、神经病学等) 的不同, 将神经血管介入的研究成果 零散地发表在全世界各种科学期刊上。为促进介入神经病学领域的知识更新、集成 和推广, 我们创立了《介入神经病学》。

《介入神经病学》杂志将在第 21 届欧洲脑卒中会议上正式启动。这将是国际上 第一本针对介入技术应用于神经系统疾病诊治的同行评议杂志。在杂志创刊初期, 《介入神经病学》将为季刊, 集中发表邀稿及投稿的综述、争鸣、荟萃分析、评论 和读者来信。后期杂志将陆续发表针对该领域热点问题的论著文章。血管内介入方 法学和技术学的新进展将成为讨论的重点。

欢迎广大同仁积极投稿！

刘新峰

MG Hennerici

里斯本, 2012 年 5 月 